\title{
Percepção da Imagem Corporal e Representações Sociais do Corpo ${ }^{1}$
}

\author{
Kenny Secchi \\ Universidade do Planalto Catarinense \\ Faculdades Integradas Univest \\ Brigido Vizeu Camargo ${ }^{2}$ \\ Universidade Federal de Santa Catarina \\ Raquel Bohn Bertoldo \\ Université Paris Descartes
}

\begin{abstract}
RESUMO - O aumento do número de pessoas com transtornos ligados à imagem corporal destacou o assunto nos âmbitos científico e midiático. Neste sentido, objetivou-se investigar a relação entre representações sociais e imagem corporal entre estudantes de diferentes cursos universitários. Participaram 278 acadêmicas dos cursos de Psicologia, Educação Física e Moda. Aplicou-se um questionário para investigar a imagem e satisfação corporal, além das representações sociais do corpo. Os resultados sugerem que apesar de apresentarem uma auto-percepção corporal normal, as estudantes estão em geral insatisfeitas com sua aparência. As representações sociais apresentaram três contextos: (1) importância da aparência e da expressão do corpo nas relações pessoais; (2) beleza e saúde corporal ligadas à magreza e à prática de exercícios físicos; e (3) aparência enquanto indicadora de potencialidades nos campos pessoal e profissional. Concluiu-se que há uma incompatibilidade entre as representações sociais e a vivência subjetiva em termos de imagem corporal.
\end{abstract}

Palavras-chave: representações sociais; corpo; imagem corporal.

\section{Body Image Perception and Body’s Social Representations}

\begin{abstract}
The increasement of people with body image disorders highlighted the issue both in science and in the media. This study's goal was to search the relation between social representations and body image among female university students from different courses. The participants were 278 students from the Psychology, Physical Education and Fashion courses. The applied questionnaire intended to investigate body's satisfaction and also social representations. The results suggest a general student's dissatisfaction with their body image, even though they perceive their body as normal. The representations of the body presented three contexts: (1) the importance of the body's look and expression in interpersonal relations; (2) beauty and health related to thinness and physical activity; (3) appearance indicating potentialities in both personal and professional fields. It was concluded that the students' social representations of the body seem to be incompatible with their body image.
\end{abstract}

Keywords: social representations; body; body image.

A imagem corporal é hoje um tema em evidência nas áreas jurídica, midiática e científica. Nessa última, vários estudos vêm sendo realizados, dada a relevância do problema em nível nacional. De acordo com o Instituto Brasileiro de Geografia e Estatística - IBGE (2004), os transtornos alimentares atingiram cerca de 38,8 milhões de pessoas na ultima década.

O modelo de beleza vem mudando, com uma diminuição significativa do manequim considerado ideal (Le Breton, 2007). Esse conflito entre o corpo real e ideal, imposto pela mídia, estimula a busca de soluções, pelas mulheres, como dietas e cirurgias plásticas, muitas vezes prejudiciais à saude fisica e mental. Observa-se assim, a multiplicação de casos de distorção da imagem corporal, que resultam em distúrbios alimentares como anorexia e bulimia.

1 Este trabalho é baseado na dissertação de mestrado da primeira autora, sob a orientação do segundo autor, desenvolvida no Programa de Pós-Graduação em Psicologia da Universidade Federal de Santa Catarina.

2 Endereço para correspondência: Av. Salvador Di Bernardi 505, Apt. 1102. São José, SC. CEP 88101-260.E-mail: brigido.camargo@yahoo. com.br.
A distorção da imagem corporal compreende a percepção do próprio corpo como mais pesado ou maior do que ele realmente é, sobretudo após a comparação com modelos de beleza na mídia (APA, 2000). Nesse sentido, a imagem corporal é uma percepção que integra os níveis físico, emocional e mental. Segundo Schilder (1977), a imagem corporal implica uma 'apercepção' do corpo, que difere da simples percepção por incluir figurações e representações mentais.

A imagem corporal é para Schilder (1977), um conceito capaz de operar com as três estruturas corporais: estrutura fisiológica, responsável pelas organizações anatomofisiológicas; estrutura libidinal, conjunto das experiências emocionais vividas nos relacionamentos humanos; e estrutura sociológica, baseada nas relações pessoais e na aprendizagem de valores culturais e sociais. A estrutura sociológica refere-se às tendências de um grupo a valorizar certas áreas ou funções, como o papel de vestes, adornos, do olhar e gestos na comunicação social. Schilder sugere, ainda, que a experiência com a imagem do próprio corpo relaciona-se à experiência de terceiros com seus corpos. Desse modo, a compreensão da problemática ligada à imagem corporal na nossa sociedade exige a consideração, além das imagens 
corporais individuais, das inter-relações entre as imagens de várias pessoas.

$\mathrm{Na}$ sociedade brasileira atual, não estar bonita pode constituir-se em grave fracasso, levando à perda da autoestima e à insegurança (Cury, 2005). A dependência da auto-estima feminina na aparência torna as mulheres mais vulneráveis à imagem corporal negativa e aos seus efeitos negativos (Castilho, 2001).

A insatisfação generalizada da mulher com o seu corpo tem sido documentada tanto em estudos realizados no Brasil (Camargo, Goetz \& Barbará, 2005; Cunha, Drozdek, Feller, Gonçalves, Simões \& Raboni, 2002; Malysse, 2003; Tavares, 2003), quanto em outros países (Armatas, Maschette \& Sands, 2004; Borchert \& Heinberg, 1996; Gardner, 1996; Harris, 1995; Kalin, Morrison \& Morrison, 2004; McCabe \& Monteath, 1997; McCabe \& Ricciardelli, 2003; Turner, Hamilton, Jacobs, Angood \& Dwyer, 1997; Webster \& Tiggemann, 2003), o que caracteriza o descontentamento com a imagem corporal como um fenômeno típico da sociedade ocidental.

O desenvolvimento da imagem corporal é intimamente ligado à estruturação da identidade no seio de um grupo social (Tavares, 2003). Partindo do conceito de imagem corporal grupal, Schilder (1977) afirma que a preocupação com a dimensão corporal, apresentada pelas pessoas que cercam o indivíduo, interfere de modo fundamental na elaboração da imagem corporal desse indivíduo. Segundo o autor, as experiências e sensações obtidas em ações e reações às relações sociais também contribuem para a estruturação da imagem corporal.

No estudo da imagem ou representação do corpo, além da ênfase psicológica, individual, desenvolvida por Schilder (1977), há uma ênfase coletiva, relacionada a opiniões e ao senso comum, teorizada por Moscovici (1976). A noção de representação social veicula, de modo sucinto, a ideia de que não existe distância entre o universo interior e exterior, do indivíduo e de seu grupo. Consequentemente, não existiria uma realidade objetiva per se, pois toda realidade seria representada, apropriada pelo indivíduo e seu grupo, reconstituída em seus universos simbólicos e integradas em seus sistemas de valores (Abric, 1994; Abric \& Guimelli, 1998; Rateau, 2007).

Esse pensamento coletivo se manifesta na comunicação, que implica o compartilhamento de uma identidade em interação com um mesmo ambiente externo. Desse modo, a comunicação veicula posições identitárias, pertenças grupais, valores e normas de toda natureza (Flament \& Rouquette, 2003). Afirma-se, portanto, que as representações são sociais porque resultam de um conjunto de interações sociais dentro de um grupo e, na medida em que são compartilhadas por seus indivíduos, marcam a diferença desse grupo em relação a outros na mesma sociedade (Guimelli, 1994).

Jodelet (1984) enfatiza a importância do estudo do corpo a partir da perspectiva das representações sociais, pois estas nos permitem identificar o caráter social da dimensão individual. As representações assumem um papel importante na elaboração de maneiras coletivas de ver e viver o corpo a partir da difusão de modelos de pensamento e de comportamento relacionados ao corpo (Jodelet, Ohana, Besis-Moñino \& Dannenmüller, 1982).
O estudo de Jodelet (1984), comparando as representações sociais do corpo em duas amostras separadas temporalmente por 15 anos (uma de 1960 e outra de 1975), observou que a primeira amostra representou o corpo em termos de um dualismo entre mente e corpo, resultado das restrições morais, físicas e sexuais. O corpo era pensado biologicamente e de modo distanciado da vivência corporal, com maior controle sobre o corpo físico. Já na segunda amostra, o corpo passa a ser visto enquanto psíquico e produto social, mais livre para a expressão da vivência prazerosa e privada. Assim, a representação social apresenta, na amostra mais recente, elementos mais hedonistas e íntimos da experiência individual, bem como imagens socialmente difundidas pela mídia que pregam juventude, vigor e beleza. Essa modificação é interpretada pela autora como o declínio da objetivação do corpo feminino, associada à difusão das ideias feministas durante os anos 60 e 70; como resultado, constata-se a complexificação da representação do corpo entre as francesas.

Partindo das investigações mencionadas, objetivou-se com o presente estudo caracterizar as representações sociais de corpo de estudantes universitárias e relacioná-las às suas imagens corporais. Além disso, buscou-se observar a relação entre esses conceitos e as formações profissionais dos participantes.

\section{Método}

\section{Participantes}

Participaram do estudo 278 estudantes de graduação, do sexo feminino, das cidades de Lages e Florianópolis, do estado de Santa Catarina. Os diferentes grupos de formação profissional foram compostos por 101 alunas de Psicologia (50 de Lages e 51 de Florianópolis), 94 alunas de Educação Física (45 de Lages e 49 de Florianópolis) e 83 alunas de Moda (41 de Lages e 42 de Florianópolis). A média de idade das alunas foi de 21 anos e 7 meses, com desvio padrão de 5 anos e 4 meses.

\section{Instrumentos}

Foi utilizado um questionário aplicado em situação coletiva, composto por seis partes: (1) variáveis descritivas (idade, local, curso); (2) peso e altura, para o cálculo do IMC (Índice de Massa Corpórea ${ }^{3}$ ); (3) imagem corporal, obtida por meio de escalas tipo Likert: percepção do próprio corpo em relação ao corpo ideal (de 1, "muito abaixo do ideal", a 5, "muito acima do ideal") e satisfação corporal (de 1, "insatisfeita", a 5, "muito satisfeita"); (4) cuidados com o corpo (prática de exercícios físicos e dietas); (5) posicionamento frente à

3 O Índice de Massa Corpórea (IMC) é uma fórmula que indica se a pessoa está com o peso ideal, considerado saudável pela Organização Mundial de Saúde - OMS (2000), acima desse peso, ou se está obeso. Para estabelecer os padrões ideais de peso, o peso atual (em $\mathrm{kg}$ ) deve ser dividido pela altura ao quadrado (em metros). Resultados possíveis: sobrepeso de $1^{\circ}$ grau ou pré-obeso (de 25 a 29,9 ), de $2^{\circ}$ grau ou obeso (de 30 a 39,9 ) e de $3^{\circ}$ grau ou obeso mórbido (acima de 40). 
cirurgia plástica estética (realização anterior de cirurgias plásticas estéticas, predisposição para realizá-las e atitudes frente a tais cirurgias), avaliado por meio de uma escala tipo Likert (de 1, "desfavorável", a 5, "muito favorável"); e (6) questão aberta para a análise da representação social de corpo (estímulo indutor "corpo").

\section{Análise de dados}

Realizou-se uma análise comparativa dos dados das estudantes dos diferentes cursos. Os dados do questionário compuseram um banco de dados, a partir do qual foram realizadas análises descritivas (frequência relativa, medida de tendência central e dispersão), de comparação de médias (teste $t$ de Student e análise de variância simples - ANOVA) e testes estatísticos não paramétricos, por meio do programa estatístico SPSS 14.0.

$\mathrm{Na}$ análise da questão aberta foi utilizado o programa Alceste - Analyse Lexicale par Contexte d'un Ensemble de Segments de Texte (Reinert, 1998). Esse programa realiza uma Análise Hierárquica Descendente a partir do corpus inicial formado pelo conjunto das respostas. A análise hierárquica descendente fornece "contextos textuais que são caracterizados pelo seu vocabulário e também segmentos de texto que compartilham esse vocabulário" (NascimentoSchulze \& Camargo, 2000, p. 297).

As classes compostas pelos contextos lexicais podem indicar representações sociais ou campos de imagens sobre um dado objeto. É o conteúdo das classes e as relações entre elas que determinará se se trata de uma representação social em seus vários aspectos ou de mais de uma representação social (Veloz, Nascimento-Schulze \& Camargo, 1999).

\section{Resultados}

\section{Imagem corporal}

O IMC foi avaliado separadamente entre os três cursos pesquisados, conforme mostrado na Figura 1. Observa-se que as universitárias de Psicologia apresentaram o maior IMC e as universitárias do curso de Moda, o menor. Entretanto, todas as três médias estão dentro do peso normal, segundo a OMS (2000). O IMC variou significativamente entre os grupos de formação profissional $\left(\mathrm{F}_{2,269}=5,51 ; p=0,05\right)$. $\mathrm{O}$ teste

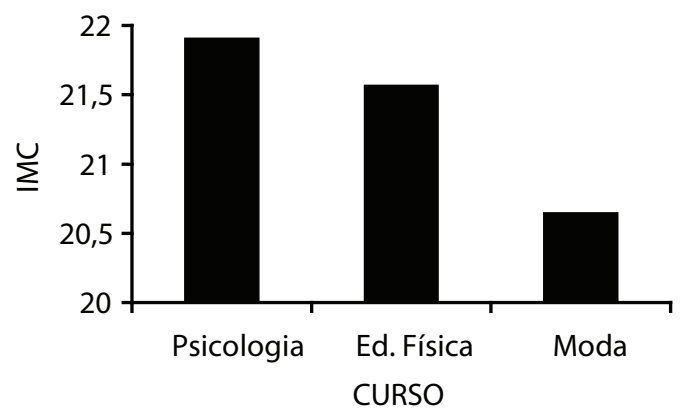

Figura 1. Média do IMC por formação profissional (N=269).

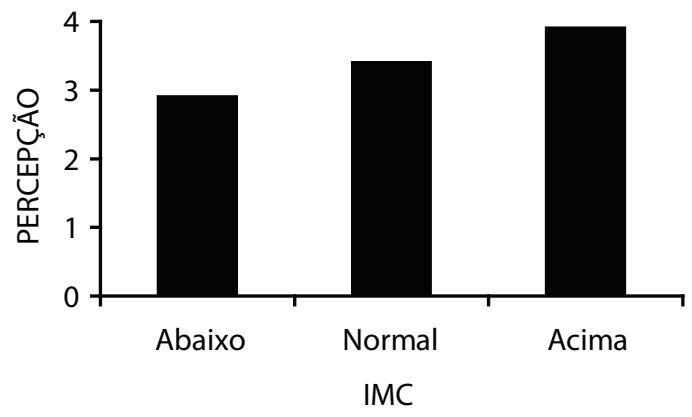

Figura 2. Relação entre percepção corporal e IMC (N=269).

à posteriori Tukey HSD indicou que o IMC das alunas de Psicologia e Educação Física em conjunto é significativamente superior ao das alunas de Moda, sendo o tamanho do efeito considerado de pequeno para médio $(d$ de Cohen $=0,40)$.

A percepção do próprio corpo atingiu uma média global de $3,45(\mathrm{DP}=0,69)$ em uma escala de 1 ("muito abaixo do ideal") a 5 ("muito acima do ideal"), com ponto médio em 3 , ou seja, ficou entre "ideal" e "acima do ideal". Ao comparar a percepção corporal das alunas com a formação profissional, percebe-se que as universitárias de Psicologia apresentaram uma média maior do que as dos demais cursos: Psicologia $(3,51)$, Educação Física $(3,48)$ e Moda $(3,34)$. Entretanto, com base na análise de variância, essas médias não diferiram significativamente $\left(\mathrm{F}_{2,275}=1,65 ; p>0,05\right)$, ou seja, as universitárias dos três cursos perceberam-se similarmente acima do ideal.

A percepção corporal foi também analisada em relação aos grupos com IMC abaixo do normal, normal e acima do normal (Figura 2). Observa-se que quanto maior o IMC, maior é a percepção da imagem corporal. AANOVA indicou que todos os grupos de IMC diferiram significativamente entre si $\left(\mathrm{F}_{2.269}=57,28 ; p<0,01\right)$, sendo o efeito considerado grande $(d$ de Cohen $=1,3)$.

Além da análise do IMC e da percepção sobre seu próprio corpo, analisou-se o quanto as universitárias estavam satisfeitas com seu corpo. As alunas atingiram uma média global de 2,78 (DP=1,15) em uma escala de 1 ("muito insatisfeita") a 5 ("muito satisfeita"), isto é, entre "insatisfeitas" e "nem satisfeitas nem insatisfeitas". Comparando a satisfação corporal com a formação profissional, os resultados apontam que as alunas de Moda apresentaram a menor média de satisfação corporal: Moda $(2,73)$, Educação Física $(2,8)$ e Psicologia (2,81). A análise de variância realizada por grupos de formação profissional indicou, entretanto, que não houve diferença estatisticamente significativa quanto à satisfação com o próprio corpo $\left(\mathrm{F}_{2,275}=0,11 ; p>0,05\right)$, ou seja, nos três cursos as universitárias estavam similarmente descontentes com seus corpos.

Conforme mostra a Figura 3, quanto maior o IMC, menor a satisfação. As diferenças entre as médias de satisfação com o próprio corpo entre os grupos com IMC abaixo do normal, normal e acima do normal são significativas $\left(\mathrm{F}_{2,269}=18,64\right.$; $p<0,01)$. O teste à posteriori Tukey HSD apresenta dois grupos mais homogêneos em relação às médias de satisfação corporal: um primeiro composto pelas alunas com IMC normal $(2,96)$ ou abaixo do normal $(3,19)$; e o segundo, com 


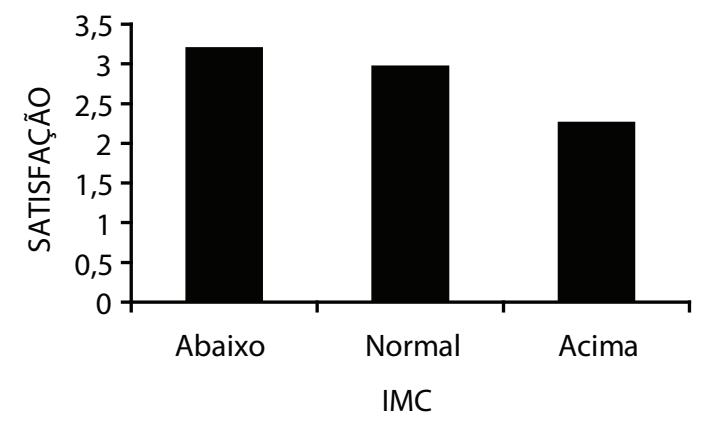

Figura 3. Relação entre satisfação corporal e IMC (N=269).

média significativamente inferior, constituído pelas alunas com IMC acima do normal (2,25). O efeito do IMC sobre a satisfação corporal pode ser considerado de médio a grande $(d$ de Cohen $=0,74)$.

\section{Cuidados com o corpo}

Em relação à prática de atividades físicas, seja por questões de saúde ou estética, 72,1\% das participantes relataram praticar exercícios físicos. Comparando o IMC à prática de exercícios físicos, observou-se que 74,4\% das mulheres com IMC abaixo do ideal, $71,4 \%$ das com IMC na faixa considerada ideal e 70,3\% das com IMC acima do ideal praticavam exercícios físicos. A análise da variância do IMC por prática ou não de exercícios físicos não apresentou diferenças estatisticamente significativas $(t=1,26 ; \mathrm{gl}=270$; $p>0,05)$. Mesmo assim, o IMC das alunas que praticavam exercícios físicos $(21,29)$ foi menor que o daquelas que não praticavam exercícios $(21,73)$.
A Figura 4 apresenta a relação significativa entre a frequência da prática de exercícios e a formação profissional. Observa-se que aproximadamente $90 \%$ das alunas de Educação Física praticam exercícios de duas a três vezes por semana ou todos os dias. As alunas de Psicologia ou de Moda, por sua vez, podem ser divididas em dois grupos: um formado por alunas que praticam exercícios de duas a três vezes por semana e outro formado por alunas que nunca praticam exercícios. Essa diferença entre os cursos deve ser o resultado da exigência da prática de atividade física pelo próprio curso de Educação Física, cujas disciplinas acadêmicas são bastante relacionadas à prática esportiva. As diferenças do padrão de atividades esportivas em função do tipo de formação profissional são estatisticamente significativas $\left(\chi^{2}=58,83 ; \mathrm{gl}=6\right.$; $p<0,01)$. A análise dos resíduos estandardizados mostra que a distribuição de frequências observada na amostra é resultado principalmente: (1) da alta frequência de alunas de Educação Física que se exercitam todos os dias $(1,6)$ e de Psicologia e de Moda que praticam esportes ao menos uma vez por mês (2,0 e 1,4 respectivamente); (2) da baixa frequência de alunas de Educação Física que se exercitam ao menos uma vez por mês $(-1,7)$ e de Psicologia que se exercitam todos os dias $(-1,9)$.

Em relação ao comportamento ligado ao corpo, também foi avaliada a adoção de dietas restritivas pelas alunas, com objetivo de perda de peso. Na Tabela 1, pode-se observar a relação estatisticamente significativa entre a adoção anterior de dietas de restrição calórica e a formação profissional $\left(\chi^{2}=16,82 ; \mathrm{gl}=6 ; p=0,01\right)$.

Percebe-se que, globalmente, 69,6\% das alunas já recorreram ao menos uma vez a dietas de restrição calórica. As alunas de Psicologia realizaram mais frequentemente dietas, uma vez que a maioria delas (78\%) já realizou ao menos uma

\section{Psicologia $\square$ Ed. Física $\square$ Moda}

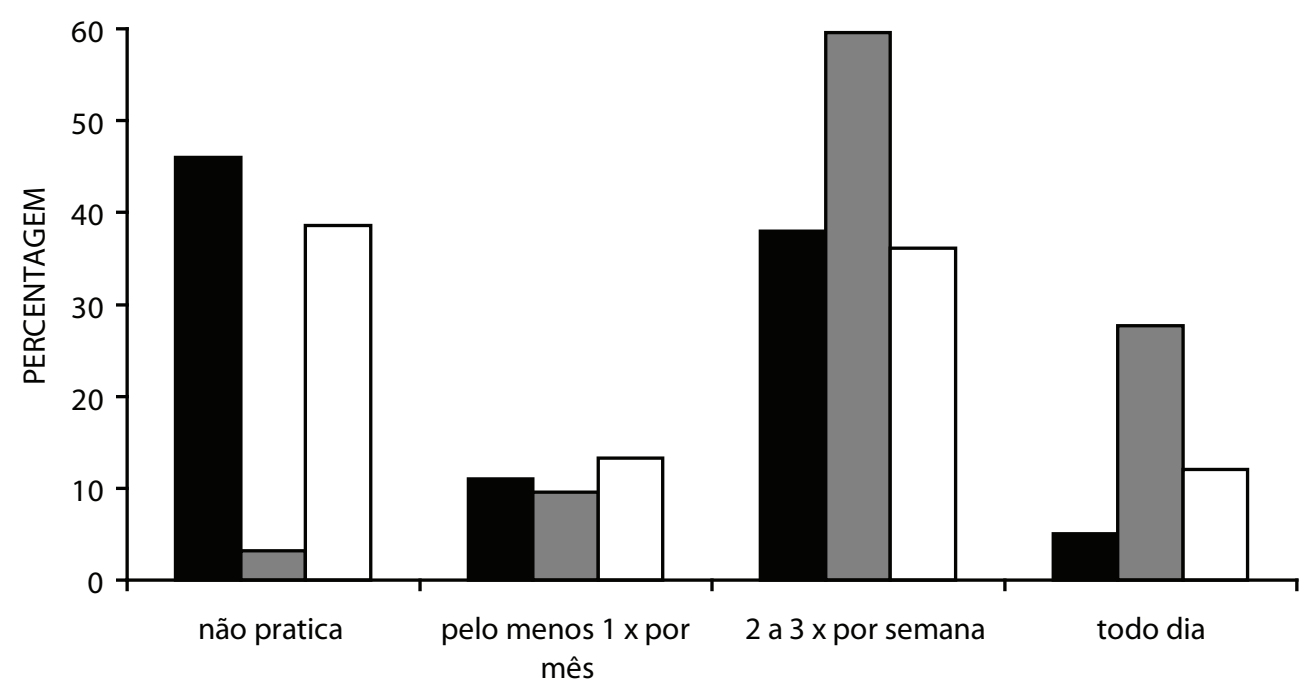

FREQUÊNCIA DA PRÁTICA DE EXERCÍCIOS

Figura 4. Frequência da prática de exercícios por formação profissional (N=277). 
Tabela 1. Prática anterior de dietas de restrição calórica por formação profissional (N=277).

\begin{tabular}{lcccc}
\hline Formação profissional & & \multicolumn{2}{c}{ Você já fez dieta? } & \\
& Nunca & Uma vez & Mais de uma vez & Muitas vezes \\
\hline Psicologia (N=100) & $22,0 \%$ & $18,0 \%$ & $33,0 \%$ & $27,0 \%$ \\
Educação Física (N=94) & $38,3 \%$ & $10,6 \%$ & $37,2 \%$ & $13,8 \%$ \\
Moda (N=83) & $31,3 \%$ & $9,6 \%$ & $25,3 \%$ & $33,7 \%$ \\
Total (N=277) & $30,3 \%$ & $13,0 \%$ & $32,1 \%$ & $24,5 \%$ \\
\hline
\end{tabular}

dieta; já as alunas de Educação Física são as que recorrem a dietas com menos frequência, mas grande parte delas $(61,6 \%)$ já realizou ao menos uma dieta restritiva. No momento da coleta, uma minoria das alunas dos três cursos fazia dieta: $19 \%$ entre alunas da Psicologia, 15\% entre as de Educação Física e 19,3\% entre as de Moda.

As alunas foram questionadas também sobre cirurgias plásticas estéticas (atitudes, realização anterior e predisposição à realização). As atitudes foram medidas a partir de uma questão em forma escalar de cinco pontos que variava de 1 ("desfavorável") a 5 ("muito favorável"). Globalmente, a atitude das alunas é positiva frente à cirurgia plástica estética $(3,33)$, isto é, entre "nem favorável nem desfavorável" e "favorável". A variação da atitude frente à cirurgia plástica nos grupos de formação profissional mostra que a média das atitudes das alunas da Psicologia $(3,29)$ foi ligeiramente maior que a das alunas da Educação Física $(3,21)$, sendo ambas menores que a média das estudantes de Moda $(3,54)$. A análise de variância mostrou, entretanto, que essas diferenças não foram estatisticamente significativas $\left(\mathrm{F}_{2,275}=2,02 ; p>0,05\right)$.

Quanto à realização anterior de cirurgia plástica estética, verificou-se que $10,4 \%$ da amostra já havia se submetido a este tipo de procedimento, percentual que não variou de modo significativo entre os grupos de formação acadêmica $\left(\chi^{2}=5,17 ; \mathrm{gl}=2 ; p>0,05\right)$ : Psicologia $(15,8 \%)$, Educação Física $(6,4 \%)$ e Moda $(8,4 \%)$.

Além da atitude frente à cirurgia plástica estética e da realização anterior desse tipo de cirurgia, foram analisadas as intenções de realizar uma dessas cirurgias no futuro. Aproximadamente metade da amostra $(49,8 \%)$ pretende realizar cirurgia plástica estética no futuro. As diferenças entre as formações profissionais não foram significativas, mas seguem a tendência observada em relação às atitudes, onde as médias das alunas de Psicologia (47,5\%) e de Educação Física $(44,7 \%)$ foram inferiores as das de Moda $(58,5 \%)$ $\left(\chi^{2}=3,7 ; \mathrm{gl}=2 ; p>0,05\right)$.

\section{Representações sociais do corpo}

O corpus composto pelas respostas abertas sobre o corpo apresentou 276 UCEs (Unidades de Contexto Elementar), das quais 255 , ou seja, $92 \%$ do total foram consideradas na Análise Hierárquica Descendente. O corpus foi formado por 17.132 ocorrências de palavras, que corresponderam a 2.124 formas distintas, indicando uma média de oito ocorrências por palavra.
Os resultados da análise hierárquica descendente são apresentados no dendograma (Figura 5), que indica as classes bem como as relações estabelecidas entre elas pela análise. Observa-se que as respostas foram inicialmente repartidas em dois sub-corpora. O primeiro relaciona a beleza do corpo à aparência, tendo posteriormente originado as classes 1 (corpo enquanto status social) e 3 (corpo como imagem e meio de comunicação). O segundo sub-corpus remete a beleza do corpo à magreza, representado pela Classe 2 (corpo belo é corpo magro e fisicamente ativo).

A Classe 1, que em conjunto com a Classe 3 opõe-se a Classe 2, foi composta por 53 UCEs, representando 20,8\% do total. O corpo é aqui pensado através da sua aparência como indicativa de potencialidades instrumentais, o que pode ser observado a partir dos radicais de noções relacionadas à classe: estética + , nariz, poder + , sabedoria, vida $+\mathrm{e}$ relacionamento + . Percebe-se que o corpo aqui é ligado ao poder no âmbito dos relacionamentos sociais, íntimos ou profissionais e é materializado enquanto instrumento visível, indicativo de possibilidades de ação. Essa classe está relacionada a estudantes do curso de Moda e, globalmente, a alunas satisfeitas com o seu corpo. A seguir, uma das UCEs componentes da Classe 1:

É instrumento utilizado para realizar tarefas, seduzir, saciar-se; orgulhar-se, interagir; transmitir sensações, ideias, conceitos, extravasar, fazer performances, chocar; induzir, convencer; cuidar. Faço a dieta do bom senso. Minha prima é nutricionista. Faço exercícios para emagrecer e para a melhoria da disposição. (estudante de Moda, 21 anos, satisfeita com seu corpo)

O contexto caracterizado pela Classe 1 apresenta o corpo sob o aspecto positivo da atividade profissional e pessoal, o que justifica a associação a pessoas que têm experiências positivas com seus corpos. A associação a estudantes de Moda parece claramente ligada ao caráter instrumental, de veículo para o produto que o corpo assume entre os profissionais dessa área.

A Classe 3, que em conjunto com a Classe 1 opõe-se a Classe 2, foi composta por 84 UCEs, representando 32,9\% do corpus. O corpo é significado nesse contexto a partir do conjunto das impressões que deixa e da expressão que permite a comunicação não-verbal, considerando-se também as trocas afetivas no contexto de relacionamentos interpessoais, o que pode ser notado através de alguns dos elementos associados à classe: expressão + , imagem + , sentimento + , primeira, amor ${ }^{+}$ e considero + . A classe é associada a alunas de Moda e, no 


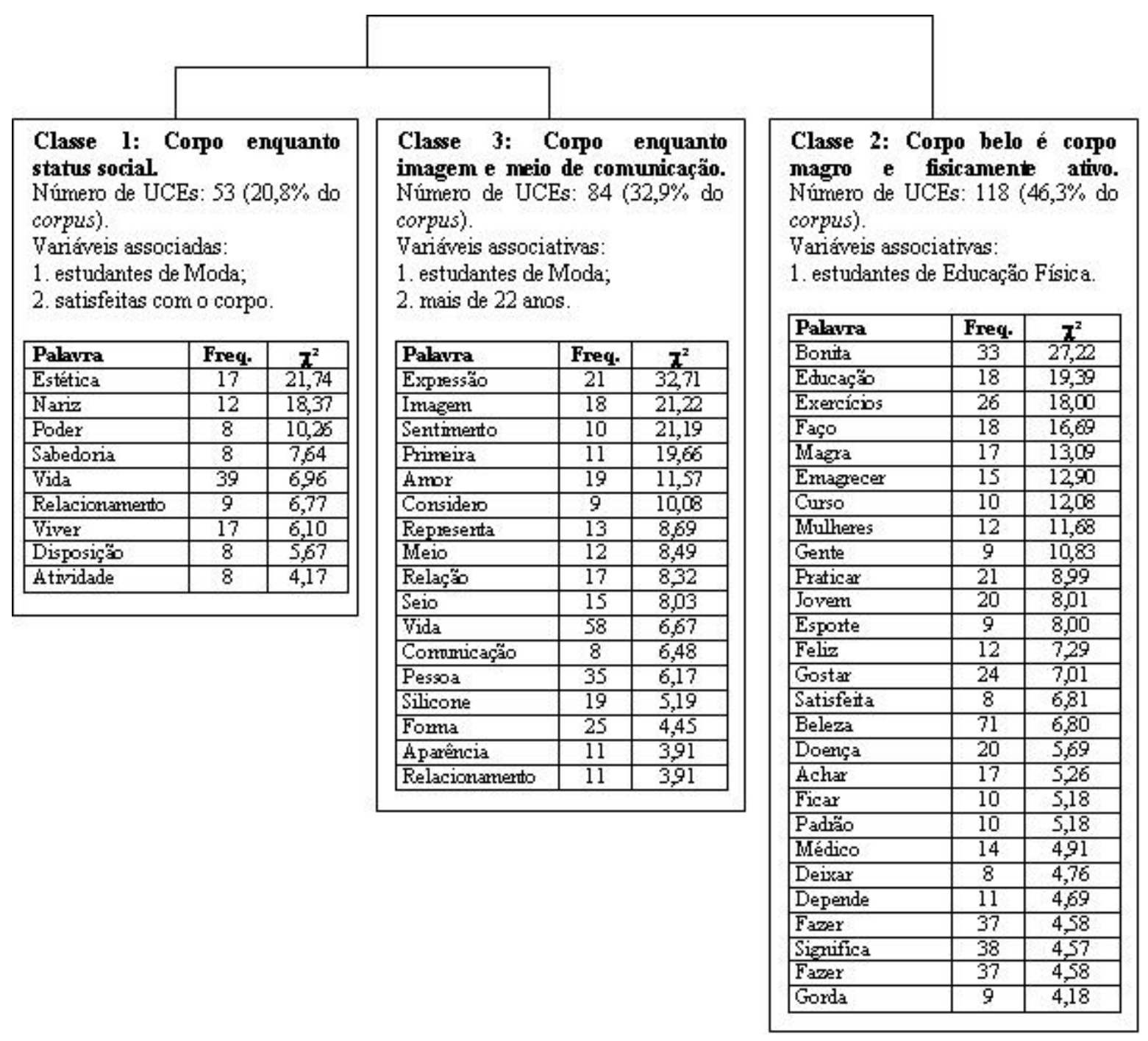

Figura 5. Dendograma da Classificação Hierárquica Descendente.

geral, a alunas maiores de 22 anos. A seguir apresenta-se uma das UCEs classificadas nesse ambiente lexical:

Corpo é o suporte para a pessoa, onde surgem suas emoções e pensamentos e o que as pessoas veem de você, o seu exterior sendo julgado. Pela saúde e pelo bem-estar. Porque a saúde é essencial, senão o corpo não funciona. O sexo está muito ligado ao corpo, ao contato e à definição dos sexos. E à beleza porque ela está muito importante para as pessoas hoje em dia. (estudante de Educação Física, 22 anos, pouco satisfeita com seu corpo)

O contexto indicado pela Classe 3 faz referência ao corpo enquanto veículo da subjetividade, como expressão de sentimentos e fonte de prazer. A expressão dessas vivências denota um grau de autoconhecimento e de familiaridade com o próprio corpo que distingue o grupo maior de 22 anos das estudantes mais jovens. A associação das estudantes de Moda à classe pode ser justificada pela atividade cotidiana do estudante da área em aperfeiçoar a expressão da personalidade e a aparência do indivíduo, a partir de tendências e padrões em voga.
A Classe 2, que se opõe ao conjunto formado pelas classes 1 e 3 , foi composta por 118 UCEs, que correspondem a 46,3\% do corpus. As respostas agrupadas nessa classe valorizam o corpo belo enquanto corpo magro e saudável, que pode ser conquistado por meio de atividades físicas, como pode ser observado a partir dos radicais das noções relacionadas à classe: bonita + , educação, exercício + , faço + , magra + e emagrecer. A Classe 2 foi associada a estudantes de Educação Física. Esse contexto é exemplificado pela seguinte UCE:

Faço exercícios, porque faço educação fisica, e para ficar como corpo modelado e durinho. O corpo tem que estar sempre bonito e nosso desempenho sexual depende de quão belo ele está, além de que o corpo tem que estar sempre saudável. (estudante de Educação Física, 20 anos, pouco satisfeita com seu corpo)

A associação do corpo ao exercício físico e da sua beleza à aparência saudável e à magreza justificam-se, sobretudo pelos padrões de beleza atuais. A associação de estudantes de Educação Física a esse contexto lexical parece remeter à própria prática acadêmica e profissional dessas estudantes, 
cujos clientes buscam frequentemente atividades físicas com fins estéticos.

\section{Discussão}

Os dados encontrados revelam que as estudantes dos cursos de Psicologia, Educação Física e Moda têm preocupação com a imagem corporal. Verificou-se que, como um todo, as estudantes percebem seus corpos entre "ideal" e "acima do ideal" e há uma insatisfação associada a essa percepção, pois globalmente elas posicionam-se entre "insatisfeita" e "nem insatisfeita nem satisfeita".

Pode-se observar também, que quanto maior o IMC, menor a satisfação em relação ao seu corpo. Novaes e Vilhena (2003) ressaltam o quanto a imagem da mulher e do feminino continua associada à beleza, havendo cada vez menos tolerância para os desvios nos padrões estéticos socialmente estabelecidos. Tomando-se a gordura como estigma da feiúra, essas autoras ressaltam a exclusão vivida pelas pessoas que estão acima do peso.

Uma das formas de minimizar a dissonância entre a imagem atual e a ideal seria a realização de cirurgias estéticas. As estudantes posicionam-se favoravelmente, já que a maioria das alunas fica entre "nem favorável nem desfavorável" e "favorável" à cirurgia plástica com fins estéticos.

A insatisfação com a imagem corporal influencia o poder, status e atração designados ao corpo, uma vez que se relacionam ao poder de atração exercido sobre o sexo oposto, em meio as suas interações sociais. Cunha e cols. (2002) também obtiveram essas evidências em seu estudo, quando analisaram mulheres e homens e sua percepção quanto ao seu corpo e o corpo atraente.

As estudantes compartilham vários aspectos da representação social de corpo. O contexto da representação relacionado à beleza e à aparência física, como sinônimos de poder nas relações interpessoais, é semanticamente próximo àquele que relaciona o corpo a um veículo da subjetividade e da personalidade, e ambos são relacionados à estudantes de Moda. Oposto a esses contextos, organiza-se outro associado a estudantes de Educação Física, que aborda a existência de padrões de beleza relacionados ao corpo feminino, estipulados socialmente e simbolizados pela saúde e pela magreza.

O grupo das estudantes do curso de Educação Física foi o que mais apontou a magreza como sua principal característica. Já o grupo das universitárias do curso de Moda foi o que mais apontou a impressão que deixamos nas outras pessoas como indicador da representação social do corpo.

A ausência de relação das acadêmicas de Psicologia com contextos representacionais específicos denota a maior complexidade representacional das estudantes desse grupo. Desse modo, o grupo profissional de Psicologia compartilha diversos aspectos da representação, ora típicos de estudantes de moda, ora de estudantes de educação física.

Resultados semelhantes foram encontrados por Camargo, Goetz e Barbará (2005), que sugerem a inclusão na representação social do corpo a ideia de que "sentir-se" bela sugere um olhar do outro favorável, e isso contribui para sua aceitação social. Nas respostas das universitárias do presente estudo isso ficou evidenciado quando descreviam os cuidados com o corpo em termos de mantê-lo magro, portanto, bonito, como condição para o bem estar.

Alguns aspectos das representações atualmente compartilhadas sobre o corpo indicam a valorização da vivência subjetiva, de certo hedonismo, tendência oposta àquela observada por Jodelet (1984) entre os anos 60 e 70, quando o corpo era pensado enquanto objeto. No entanto, foi também identificada uma crescente atenção aos padrões de beleza na mídia cujo efeito foi identificado no presente estudo, ou seja, o descontentamento com o próprio corpo.

\section{Considerações Finais}

O corpo feminino é, portanto, representado como algo que deve ser dotado de beleza, magreza, poder e status, exercer atração e, além disso, ser saudável. Contudo, esse corpo está longe de ser o ideal, uma vez que a imagem corporal desejada pelas mulheres pesquisadas encontra-se abaixo do peso considerado normal pela OMS.

O impacto de padrões estritos de beleza e o compartilhamento de representações sociais do corpo sobre a insatisfação corporal feminina devem ser compreendidos dentro de uma arquitetura de pensamento social (Rouquette, 1996). As ideologias liberais que influenciam fortemente nossa sociedade nesse início de século enquadram as representações de objetos sociais e estas, por sua vez, determinam as atitudes (nível individual), opiniões (nível interindividual) e percepções (nível intra-individual) (Doise, 1982). As representações sociais compartilhadas pelos grupos de estudantes parecem, portanto, determinar a intensidade da insatisfação corporal das estudantes, como foi observado no contexto representacional da Classe 3. Deve-se fazer a ressalva de que a amostra foi composta por alunas universitárias (média de idade de 21 anos e 7 meses), entre as quais a implicação da auto-imagem às aspirações de poder através da beleza e do poder de atração do sexo oposto é mais acentuada. É bastante provável que estudos com mulheres de outras faixas etárias identificassem elementos diferentes.

\section{Referências}

Abric, J. C. (1994). Pratiques sociales et représentations. Paris: PUF.

Abric, J. C., \& Guimelli, C. (1998). Représentations sociales et effets de contexte. Connexions, 72, 23-37.

Associação Psiquiátrica Americana (2000). DSM-IV, Manual diagnóstico e estatístico de transtornos mentais ( $\left.4^{\mathrm{a}} \mathrm{ed}\right)$. Porto Alegre: Artes Médicas.

Borchert, J., \& Heinberg, L. (1996). Gender schema and gender role discrepancy as correlates of body image. The Journal of Psychology, 130, 547-559.

Camargo, B. V., Goetz, E. R., \& Barbará, A. (2005). Representação social da beleza de estudantes de moda. Em Universidade Federal da Paraíba (Org.), Textos completos da IV Jornada Internacional e II Conferência Brasileira sobre Representações Sociais (Meio Digital). João Pessoa: UFPB.

Castilho, S. M. (2001). A imagem corporal. Santo André: ESETec. 
Cunha, D. W., Drozdek, S., Feller, E. L. B., Gonçalves, F. L., Simões, E. A. Q. \& Raboni, M. R. (2002). Sentimento de inadequação na percepção do próprio corpo. Psychê, 7 (2), 1-56.

Cury, A. (2005). A ditadura da beleza e a revolução das mulheres. Rio de Janeiro: Sextante.

Doise, W. (1982). L'explication en psychologie sociale. Paris: PUF.

Flament, C., \& Rouquette, M. L. (2003). Anatomie des idées ordinaires : Comment étudier les représentations sociales. Paris: Armand Colin.

Gardner, R. M. (1996). Methodological issues in assessment of the perceptual component of body image disturbance. British Journal of Psychology, 87, 327-337.

Guimelli, C. (1994). Structures et transformation des représentations sociales. Neuchâtel: Delachaux et Niestlé.

Harris, S. M. (1995). Body image attitudes and the psychosocial development of college women. The Journal of Psychology, 129, 315-329.

IBGE (2004). Síntese dos indicadores sociais. Retirado em 02/06/2006, de http://www.ibge.gov.br/home/estatistica/populacao/ condicaodevida/indicadoresminimos/sinteseindicsociais2004/ default.shtm.

Jodelet, D. (1984). The representation of the body and its transformations. Em R. Farr \& S. Moscovici (Orgs.), Social representations (pp. 211-238). Cambridge: Cambridge University Press.

Jodelet, D., Ohana, J., Bessis-Moñino, C., \& Dannenmüller, E. (1982). Système de représentation du corps et groupes sociaux. (Relatório Técnico). Paris : Laboratoire de Psychologie Sociale de l'EHESS.

Kalin, M., Morrison, A., \& Morrison, T. G. (2004). Body-image evaluation and body-image investment among adolescents: A test of sociocultural and social comparison theories. Adolescence, 39, 571-592.

Le Breton, D. (2007). Adeus ao corpo: antropologia e sociedade. Campinas: Papirus.

Malysse, S. (2003). Um ensaio de antropologia visual do corpo. Em B. Lyra \& W. Garcia (Orgs.), Corpo e imagem (pp. 65-75). São Paulo: Arte \& Ciência.

McCabe, M. P., \& Monteath, S. A. (1997). The influence of societal factors on female body image. Journal of Social Psychology, 137, 708-727.

McCabe, M. P., \& Ricciardelli, L. A. (2003). Sociocultural influences on body image and body changes among adolescent boys and girls. Journal of Social Psychology, 143, 5-26.
Moscovici, S. (1976). La psychanalyse, son image et son public. Paris: PUF.

Nascimento-Schulze, C. M., \& Camargo, B. V. (2000). Psicologia social, representações sociais e métodos. Temas de Psicologia, 8, 287-299.

Novaes, J. V., \& Vilhena, J. (2003). De cinderela à moura torta: sobre a relação mulher, beleza e feiúra. Revista Interações, 8, 9-36.

Organização Mundial de Saúde - OMS (2000). CID - 10: classificação estatística internacional de doenças e problemas relacionados à saúde. São Paulo: Edusp.

Rateau, P. (2007). Les représentations sociales. Em G. Amy \& M. Piolat (Orgs.), Psychologie sociale (pp. 164-218). Paris: Bréal.

Reinert, M. (1998). Alceste: Analyse de données textuelles. Manuel d'utilisateur. Toulouse: IMAGE.

Rouquette, M. L. (1996). Représentations et idéologie. Em J. C. Deschamps \& J. L. Beauvois (Eds.), Des attitudes aux attributions (pp. 163-173). Grenoble: Presses Universitaires de Grenoble.

Schilder, P. (1977). A imagem do corpo. Buenos Aires: Paidós.

Tavares, M. C. G. C. (2003). Imagem corporal: conceito e desenvolvimento. São Paulo: Manole.

Turner, S. L., Hamilton, H., Jacobs, M., Angood, L. M., \& Dwyer, D. H. (1997). The influence of fashion magazines on the body image satisfaction of college women: An exploratory analysis. Adolescence, 32, 603-614.

Veloz, M. C. T., Nascimento-Schulze, C. M., \& Camargo, B. V. (1999). Representações sociais do envelhecimento. Psicologia: Reflexão e Crítica, 12, 479-501.

Webster, J. \& Tiggemann, M. (2003). The relationship between women's body satisfaction and self-image across the life span: The role of cognitive control. Journal of Genetic Psychology, 164, 241-252. 